\title{
Atendimento em clínicas-escola de psicologia da região metropolitana de Porto Alegre
}

\author{
The university-psychology-clinic's treatment in Porto Alegre's \\ metropolitan area
}

\author{
Paula von Mengden CAMPEZATTO \\ Maria Lúcia Tiellet NUNES ${ }^{3}$
}

\begin{abstract}
Resumo
Levantamentos realizados em clínicas-escola de cursos de Psicologia nas décadas de 1980 e 1990 indicaram que os atendimentos oferecidos são ineficientes. Há escassez, no entanto, de publicações de atividades dessa natureza no Estado do Rio Grande do Sul. Este trabalho se propôs a realizar uma pesquisa quantitativa, descritiva e de levantamento das modalidades terapêuticas e abordagens teóricas empregadas nas clínicas-escola da região metropolitana de Porto Alegre, caracterizar procedimentos de triagem e do atendimento propriamente dito, e verificar os índices de reencaminhamento, conclusão e abandono de tratamento nas instituições. Os principais achados apontam para uma pluralidade de modalidades terapêuticas e abordagens teóricas em todas as clínicas-escola pesquisadas. Dos clientes, 11,88\% foram reencaminhados para outras instituições, 38,21\% abandonaram os atendimentos e 15,79\% receberam alta - índices positivos quando comparados à literatura.
\end{abstract}

Unitermos: atendimento psicológico; clínica-escola; desistência do tratamento; psicologia preventiva; psicoterapia.

\begin{abstract}
Survey's research about clients form University Psychology Clinics in the 80's and 90's indicated that the psychological services were inefficient. Although many studies about University Psychology Clinics have been conducted in Brazil, there are few in Rio Grande do Sul. This study is a research about therapeutic practices and theoretical orientation modality developed at University Psychology Clinics from Porto Alegre Metropolitan Region. The present paper also describes patient's screening and helping processes, as well as verifies index of other institutions' referring, treatmentending and dropping out. Data indicates many kinds of therapeutic practices and theoretical orientation in all University Psychology Clinics of this research. 11.88\% of the clientele were referred to other institutions, 38.21\% have given up the attending process and 15.79\% of the patients discharged: positive results comparing to the literature.
\end{abstract}

Uniterms: psychological service; school-clinics; treatment dropouts; preventive psychology; psychotherapy.

1 Artigo elaborado a partir da dissertação de P. von M. CAMPEZATTO, intitulada "As clínicas-escola de cursos de psicologia da região metropolitana de Porto Alegre". Porto Alegre, 2006. Apoio: bolsa CNPq

2 Pontifícia Universidade Católica do Rio Grande do Sul, Curso de Psicologia Clínica. Av. Ipiranga, 6681, Prédio 11, 9ªndar, Sala 928, 90619-900, Porto Alegre, RS, Brasil. Correspondência para/Correspondence to: P. von M. CAMPEZATTO. E-mail: <paulavmc@hotmail.com>.

3 Pontifícia Universidade Católica do Rio Grande do Sul, Programa de Pós-Graduação em Psicologia. Porto Alegre, RS, Brasil. 
Quando regulamentada a profissão do psicólogo pela Lei n. 4.119, em 27 de agosto de 1962, foi referido que cada curso de Psicologia deveria organizar serviços de atendimento para que os alunos, sob supervisão docente, praticassem o que Ihes foi ensinado nas disciplinas da graduação (Brasil, 1962). Esses serviços, conhecidos como clínicas-escola, passaram a constituir tanto locais onde os alunos da graduação pudessem exercer os estágios e aplicar o que aprenderam nas disciplinas, como oferta, feita pela universidade, de prestação de serviços de atendimento psicológico, gratuito ou semigratuito, à comunidade (Güntert et al., 2000).

Pesquisas realizadas em clínicas-escola brasileiras, nas décadas de 1980 e 1990, indicaram uma taxa elevada de evasão dos atendimentos, o que mostra que os atendimentos oferecidos são ineficientes (Ancona-Lopez, 1983; Silvares, 1996). Para Ancona-Lopez (1983), esse dado demonstra que tais instituições funcionam de forma bastante contraditória na medida em que a maioria da clientela que busca por atendimento psicológico é encaminhada ou permanece em longas listas de espera, sendo pouquíssimos os casos que recebem atendimento e alcançam os objetivos propostos.

Tendo em vista que as técnicas psicológicas tradicionais não foram desenvolvidas em nosso país, nem direcionadas à população de nível socioeconômico e cultural baixo, por vezes é perceptível uma incompatibilidade entre o que o cliente necessita e aquilo que é oferecido (Ancona-Lopez, 1983; Barbosa \& Silvares, 1994; Carvalho \&Telles, 2001). Além disso, Peres (1997) lembra que o psicólogo se encontra despreparado para enfrentar as mudanças sociais que ocorreram no Brasil em função de uma formação em Psicologia considerada defasada em três décadas, tendo em vista as poucas mudanças nos elencos das disciplinas.

Assim Peres (1997) afirma que muitas clínicas-escola parecem desconhecer as reais necessidades da clientela que as procura e, portanto, correm o risco de não prestarem serviços adequados. Diante disso, profissionais e pesquisadores passaram a refletir sobre a necessidade de revisão de algumas técnicas já cristalizadas no ensino e na prática da Psicologia, visando atender tanto as especificidades da clientela, como a formação adequada do alunado (Enéas, Faleiros
\&Sá, 2000; Romaro \& Capitão, 2003), que, muitas vezes, toma contato com um único modelo de atuação clínica, tendendo a reduzir as possibilidades futuras de aplicação dos conhecimentos da área, reproduzindo apenas o aplicado no estágio.

Essas inovações práticas são relatadas em diversos artigos sobre o tema, os quais propõem intervenções breves e muito breves (Ramires, 2000), atividades em grupo com o intuito de atender a um número maior de pacientes (Henriques, 1998), deslocamento do profissional às comunidades que buscam atendimento na clínica-escola com o objetivo de realizar um trabalho profilático (Silvares, 2000) e a revisão dos processos de acolhimento e triagem, buscando reduzir o tempo de espera por atendimento e o índice de reencaminhamento para outros locais (Graminha \& Martins, 1991; Peres, 1997; Salinas \& Gorayeb, 2002; Salinas \& Santos, 2002).

Apesar de ser possível encontrar, em periódicos científicos da área de Psicologia, diversas produções que abordam a temática das clínicas-escola, percebe-se a escassez de publicações de experiências oriundas do Rio Grande do Sul, estado que concentra 23 cursos de Psicologia. Foi encontrada uma pesquisa específica sobre o ensino da Psicologia Clínica em cursos de Psicologia do Estado realizada há oito anos por Furtado (1997). A partir dos programas da referida disciplina em dez universidades, a autora constatou que é grande a influência psicanalítica na prática clínica nas faculdades de Psicologia desde o início dos cursos no Rio Grande do Sul, sendo a Psicoterapia o principal conteúdo ministrado, aliado basicamente aos moldes da teoria psicanalítica, considerando seus principais conteúdos e autores clássicos.

Diante do exposto, o objetivo deste estudo é conhecer as modalidades terapêuticas e as abordagens teóricas empregadas nas clínicas-escola da região metropolitana de Porto Alegre, verificando como são as práticas acadêmicas da Psicologia clínica nos dias atuais, passados oito anos do estudo de Furtado (1997). Esta pesquisa se propõe, além disso, a caracterizar procedimentos de triagem e do atendimento propriamente dito, bem como verificar os índices de reencaminhamento, conclusão e abandono de tratamento nas instituições. 


\section{Método}

Este trabalho constituiu uma pesquisa quantitativa, descritiva e de levantamento metodologia bastante eficaz para apurar e descrever os dados, pois possibilita um conhecimento amplo de uma realidade, abrindo caminhos para hipóteses futuras (Gil, 1999). Partindo desses pressupostos, o delineamento da pesquisa se deu a partir de fatores que beneficiem a coleta dos dados, ou seja, a possibilidade de atingir um maior número de instituições, menores gastos, rapidez na obtenção dos resultados, garantia do anonimato dos sujeitos, além de permitir que as pessoas respondam ao questionário no momento em que julguem conveniente (Goodwin, 1995).

\section{Participantes}

A fonte de informações é oriunda dos atendimentos realizados no ano de 2004 em todas as clínicas-escola vinculadas aos cursos de Psicologia, distribuídas na região metropolitana de Porto Alegre e representadas por seus coordenadores. Nessa região, situam-se 10 dos 23 cursos de Psicologia existentes no Estado do Rio Grande do Sul, com os quais foram realizados contatos prévios para apresentar os objetivos da pesquisa à direção científica e/ou de ensino do local.

Dentre as dez clínicas-escola convidadas a participar deste estudo, uma delas não respondeu a nenhuma das tentativas de contato das pesquisadoras - telefonema, correspondência e correio eletrônico -, sendo desconsiderada da pesquisa. Outra clínica-escola, pertencente a um curso de Psicologia ainda recente, apresentou como justificativa para não responder à pesquisa o fato de a clínica-escola ainda estar em tratativas de regulamentação com o Ministério da Educação e Cultura (MEC), não sendo, portanto, local de estágio para os alunos da graduação. Como não foi possível contar com os dados dessas clínicas-escola, os resultados deste estudo são relativos a oito dessas instituições.

\section{Instrumentos}

Foi utilizado como instrumento de pesquisa um questionário cuja elaboração se deu por meio de um levantamento amplo e aprofundado da literatura pertinente. O questionário foi construído de forma a contemplar as informações necessárias para atingir os objetivos deste estudo, dispostas em questões objetivas e abertas, de múltipla escolha, inspirado no instrumento elaborado por Ghazzi (2000) para levantar dados a respeito de características do trabalho de estimulação precoce no Rio Grande do Sul.

Em uma primeira parte do questionário, são verificadas as características dos atendimentos prestados por clínicas-escola (localização da clínica-escola, locais onde as atividades são exercidas, modalidades terapêuticas, abordagens teóricas, modo como são realizadas atividades de triagem, uso ou não de termo de consentimento livre e esclarecido, critérios para receber atendimento na instituição e critérios de alta terapêutica), bem como as características clínicas da população atendida (número de atendimentos, altas e abandonos). Na segunda parte, as questões são relativas a características sociodemográficas da população atendida na clínica-escola (sexo, idade, estado civil, ocupação, escolaridade, renda familiar), dados explorados em outro artigo derivado deste mesmo estudo.

\section{Procedimentos}

Para realizar a coleta de dados, o questionário foi entregue a cada sujeito, pessoalmente ou via correio, dentro de um envelope lacrado, juntamente com uma carta de apresentação, explicando o porquê da pesquisa, por quem deveria ser respondida e assegurando a não-identificação dos respondentes. Juntamente com os questionários, foram enviados envelopes selados endereçados às pesquisadoras para viabilizar o retorno do instrumento.

Os dados quantitativos, oriundos de questões objetivas, foram organizados em um banco de dados e analisados a partir de estatística descritiva (SPSS for Windows, versão 11.5). As questões abertas e de múltipla escolha foram submetidas à análise de conteúdo (Bardin, 1988).

Os respondentes receberam um termo de consentimento livre e esclarecido, convidando-os a participar desta pesquisa, o qual foi assinado e devolvido às pesquisadoras. Este estudo foi aprovado pela comissão científica da Faculdade de Psicologia e pelo Comitê de Ética em Pesquisa da Pontifícia Universidade Católica do Rio Grande do Sul. 


\section{Resultados}

As clínicas-escola que aceitaram participar deste estudo são listadas na Tabela 1, seguindo nomenclatura fictícia, e acompanhadas pela listagem dos locais onde os acadêmicos exercem suas práticas. Três clínicas-escola (A, B, G) solicitaram auxílio das pesquisadoras na coleta de alguns dos dados necessários para responder ao instrumento, bem como para constituir um banco de dados. As demais $(C, D, E, F, H)$ seguiram as instruções propostas, devolvendo o questionário preenchido conforme solicitado na carta de apresentação e nas instruções de preenchimento.

As clínicas-escola participantes deste estudo localizam-se nos próprios campi universitários, com exceção da clínica-escola F, que se localiza no centro da cidade. Nem todas as atividades, todavia, são exercidas nas próprias sedes (Tabela 1).

Verifica-se que a maioria das clínicas-escola (6/ 8) apresentadas na Tabela 1 não realiza suas atividades unicamente na própria sede, mas também nas comunidades (em centros comunitários, instituições escolares ou em postos de saúde conveniados). Por meio das atividades desenvolvidas pelos estagiários na comunidade, pode-se perceber a importância do deslocamento do psicólogo para o meio em que os seus assistidos residem, conforme enfatiza Mejias (1995): se a população não pode ir ao psicólogo, o profissional pode ir até ela. Dessa forma, o estagiário conhece a realidade da comunidade e atende aos que necessitam e conhecem seus serviços, como também aos que sequer sabem que poderiam ser auxiliados por um psicólogo.

Essa prática, muitas vezes, não é incentivada nas ou pelas instituições de saúde pública por fugir dos padrões de atuação tradicionais do psicólogo, uma vez que o modelo clínico de psicoterapia individual ainda é predominante nos serviços públicos, atendendo não só a desejos da instituição como também da própria clientela (Seidl \& Costa Júnior, 1999). Modelos alternativos inspirados na Psicologia da Saúde podem, todavia, favorecer resultados mais eficazes, diretos e rápidos.

A questão do planejamento de programas preventivos de atenção primária também vem sendo alvo de atenção de estudiosos do assunto. Em uma pesquisa na clínica-escola da USP, Silvares (1993) constatou que pais mais escolarizados encaminham seus filhos à clínica em idade mais precoce do que os menos escolarizados. Os pais pouco escolarizados atribuem esse papel à escola, utilizando-a como intermediária para identificar o problema da criança. A autora destaca que é mais eficaz a ida da clínica até essas crianças com programas preventivos do que aguardar sua vinda à clínica, após anos de repetência escolar.

Com base nos estudos de caracterização da clientela e dos serviços prestados por essas clínicasescola em São Paulo, Silvares (2000) experimentou com sucesso uma inversão do fluxo usual do paciente até a clínica-escola, com intenção de prevenir a evasão dos atendimentos.

Partindo do pressuposto de que as clínicasescola, em geral, localizam-se em pontos distantes das moradias de sua clientela, que precisa de condução sem que tenha recursos financeiros para tanto, a autora propôs uma intervenção psicológica na própria sede da escola que mais encaminhava pacientes para atendimento. A proposta culminou na adoção de programas aplicados na comunidade e permitiu ao estagiário conhecer a atuação psicológica de caráter preventivo, sem excluir a possibilidade de detectar possíveis dificuldades individuais em alguns sujeitos, realizando ou não um encaminhamento que atenda às suas necessidades.

Tabela 1. Local em que ocorrem as atividades exercidas pela equipe das clínicas-escola.

\begin{tabular}{|c|c|c|c|c|c|c|c|}
\hline A & B & C & D & E & $\mathrm{F}$ & G & $\mathrm{H}$ \\
\hline $\begin{array}{l}\text { Clínica-escola } \\
\text { Instituição } \\
\text { escolar } \\
\text { Centro } \\
\text { comunitário }\end{array}$ & Clínica-escola & $\begin{array}{l}\text { Clínica-escola } \\
\text { Instituição } \\
\text { escolar } \\
\text { Centro } \\
\text { comunitário } \\
\text { Posto de saúde } \\
\text { conveniado }\end{array}$ & $\begin{array}{l}\text { Clínica-escola } \\
\text { Centro } \\
\text { comunitário }\end{array}$ & Clínica-escola & $\begin{array}{l}\text { Clínica-escola } \\
\text { Instituição escolar } \\
\text { Centro } \\
\text { comunitário }\end{array}$ & $\begin{array}{l}\text { Clínica-escola } \\
\text { Instituição escolar } \\
\text { Outros locais do } \\
\text { campus } \\
\text { universitário }\end{array}$ & $\begin{array}{l}\text { Clínica-escola } \\
\text { Centro } \\
\text { comunitário }\end{array}$ \\
\hline
\end{tabular}


Da mesma forma, a experiência do estágio curricular na clínica-escola da PUCRS incentiva a promoção da saúde à sua clientela, disponibilizando atendimentos grupais de caráter preventivo em centro comunitário, pré-escola e instituição de abrigo para idosos (Campezatto, Menegat, Nunes \& Vitola, 2005).

A criação desses programas de atendimento com orientação comunitária e de ensino poderiam auxiliar os pacientes a enfrentar suas dificuldades pessoais e, ao mesmo tempo, proporcionar ao estagiário uma formação profissional mais completa (Terzis \& Carvalho, 1988). Santos (1990) ressalta que, sem a ênfase do objetivo de cura, mas com a proposta de promover a saúde, poderia haver um vínculo mais forte entre a clínica e as famílias, as quais seriam capazes de encaminhamentos mais adequados e realistas e com um índice reduzido de desistências e abandonos.

Pode-se verificar na Tabela 2, uma variedade tanto nas abordagens teóricas utilizadas como nas modalidades terapêuticas oferecidas à clientela, o que retrata que a imagem distorcida do psicólogo unicamente como psicoterapeuta individual, profissional liberal, trabalhando em consultórios privados, não é mais o único modelo presente nesses cursos de graduação.

Em 1992, Schmidt ainda retratava que os modelos de atendimento ensinados nos cursos de graduação, semelhantes aos do consultório particular, não eram sensíveis às demandas de uma clientela diversificada; delineava modelos incompatíveis entre os objetivos traçados para o ensino e as necessidades de atendimento adequado a quem procura ajuda. Passada uma década, é possível encontrar uma diversidade de modelos teóricos - os quais podem ser escolhidos pelo alunado para constituir uma identidade profissional coerente com o próprio desejo - e uma variedade de intervenções que oferecem alternativas adequadas às necessidades de quem busca atendimento na clínica-escola.

Ramires (2000) relata que na clínica-escola da Universidade do Vale do Rio dos Sinos (Unisinos) existem intervenções nas modalidades de Psicoterapia Psicanalítica propriamente dita, Psicoterapia Breve de Orientação Psicanalítica e Psicoterapia de Apoio, além de interconsultas e acompanhamento de casos em

atendimento pela Nutrição ou Enfermagem. Retrata, também, a experiência de intervenções muito breves,

Tabela 2. Distribuição das clínicas-escola por abordagem teórica e modalidades terapêuticas.

\begin{tabular}{|c|c|c|}
\hline & Abordagens teóricas & Modalidades terapêuticas \\
\hline A & $\begin{array}{l}\text { Psicanálise } \\
\text { Humanismo-existencial }\end{array}$ & $\begin{array}{l}\text { Psicoterapia breve individual } \\
\text { Grupo de encontro e grupo } \\
\text { operativo } \\
\text { Intervenção em crise } \\
\text { Avaliação psicológica/ } \\
\text { psicodiagnóstico }\end{array}$ \\
\hline B & $\begin{array}{l}\text { Psicanálise } \\
\text { Psicologia sistêmica } \\
\text { Psicopedagogia }\end{array}$ & $\begin{array}{l}\text { Psicoterapia individual } \\
\text { Terapia de casal e família } \\
\text { Grupos de sala de espera } \\
\text { Psicopedagogia }\end{array}$ \\
\hline C & $\begin{array}{l}\text { Psicanálise } \\
\text { Humanismo-existencial } \\
\text { Cognitivo-comportamental } \\
\text { Psicologia sistêmica }\end{array}$ & $\begin{array}{l}\text { Psicoterapia focal individual } \\
\text { Terapia de casal e família } \\
\text { Grupo operativo e grupos de } \\
\text { sala de espera } \\
\text { Avaliação psicológica/ } \\
\text { psicodiagnóstico }\end{array}$ \\
\hline D & $\begin{array}{l}\text { Psicanálise } \\
\text { Cognitivo-comportamental } \\
\text { Humanismo }\end{array}$ & $\begin{array}{l}\text { Psicoterapia breve ou focal } \\
\text { individual } \\
\text { Psicoterapia de apoio } \\
\text { Intervenção em crise } \\
\text { Avaliação psicológica/ } \\
\text { psicodiagnóstico } \\
\text { Interconsulta psiquiátrica }\end{array}$ \\
\hline E & $\begin{array}{l}\text { Psicanálise } \\
\text { Humanismo-Existencial }\end{array}$ & $\begin{array}{l}\text { Psicoterapia individual } \\
\text { Psicoterapia focal individual } \\
\text { Terapia de grupo e grupos de } \\
\text { sala de espera } \\
\text { Psicodiagnóstico } \\
\text { Acolhimento a vítimas de } \\
\text { violência }\end{array}$ \\
\hline $\mathrm{F}$ & $\begin{array}{l}\text { Psicanálise } \\
\text { Cognitivo-comportamental } \\
\text { Psicologia sistêmica }\end{array}$ & $\begin{array}{l}\text { Psicoterapia individual } \\
\text { Psicoterapia de apoio } \\
\text { Psicoterapia breve ou focal } \\
\text { individual } \\
\text { Terapia de grupo e grupos de } \\
\text { encontro } \\
\text { Terapia mãe-bebê } \\
\text { Avaliação psicológica/ } \\
\text { psicodiagnóstico }\end{array}$ \\
\hline G & $\begin{array}{l}\text { Psicanálise } \\
\text { Cognitivo-comportamental } \\
\text { Psicologia sistêmica }\end{array}$ & $\begin{array}{l}\text { Psicoterapia individual } \\
\text { Psicoterapia breve individual } \\
\text { Psicoterapia de apoio } \\
\text { individual } \\
\text { Psicoterapia de grupo } \\
\text { Terapia de casal e família } \\
\text { Avaliação psicológica/ } \\
\text { psicodiagnóstico } \\
\text { Orientação profissional } \\
\text { Avaliação neuropediátrica } \\
\text { Aconselhamento }\end{array}$ \\
\hline $\mathrm{H}$ & $\begin{array}{l}\text { Psicanálise } \\
\text { Fenomenológico-existencial } \\
\text { Cognitivo-comportamental }\end{array}$ & $\begin{array}{l}\text { Psicoterapia individual } \\
\text { Psicoterapia focal individual } \\
\text { Psicoterapia de grupo e grupo } \\
\text { operativo } \\
\text { Psicoterapia mãe-bebê } \\
\text { Psicodiagnóstico }\end{array}$ \\
\hline
\end{tabular}


com duração de quatro entrevistas em média, que buscam a eliminação da lista de espera e possibilitam o atendimento da clientela de acordo com a necessidade.

Ainda no que diz respeito à experiência dessa instituição, Dirani (2000) descreve uma forma de atuar na clínica psicológica que nem sempre se caracteriza como Psicoterapia, embora possa apresentar momentos terapêuticos. Descreve as chamadas 'intervenções breves', que necessitam que o terapeuta se coloque como um 'psicólogo clínico geral', disponível às diferentes demandas que se apresentam e aponte o caminho a ser percorrido pelo paciente. Na Tabela 2 podem ser verificadas modalidades terapêuticas de caráter focal ou breve em diversas clínicas-escola, além de intervenções em crise que corroboram as idéias dos autores acima citados.

Com a proposta de reduzir o índice de evasão em clínica-escola, Guerrelhas \& Silvares (2000) propuseram com sucesso uma modalidade de atendimento denominada'grupos de espera recreativos', que consiste em uma abordagem recreativa, sem objetivos terapêuticos. Possibilitou-se a inserção de alunos dos primeiros anos do curso de graduação em Psicologia nas clínicas-escola que brincavam com crianças que aguardavam atendimento em lista de espera. Da mesma forma, os 'grupos de sala de espera', mencionados na Tabela 2, tendem a atender tais objetivos.

Henriques (1998) também apresenta um breve relato de evolução dos pacientes idosos submetidos à Psicoterapia grupal em uma clínica-escola. Observou que, por meio do grupo, houve um intercâmbio de vivências a partir de temáticas comuns, proporcionando a revisão de projetos pessoais, ampliação da escuta e identificação de movimentos internos que se reproduziram dentro e fora do grupo. Por outro lado, a clínica-escola, por meio das atividades grupais, propiciou a intervenção direta a um número maior de pessoas do que com atendimentos individuais usuais.

Todas as clínicas-escola participantes deste estudo realizam um processo de recepção dos pacientes, denominado 'triagem', mas podendo também ter nomenclaturas como'entrevistas iniciais' ou'entrevistas de acolhimento.' Apenas a clínica-escola F utiliza uma escala auxiliar nesse processo, o Child's Behavior Checklist $368(\mathrm{CBCL})$.
Na maioria das clínicas-escola (A, C, D, E, F, G e H), o paciente assina um 'Termo de Consentimento Livre e Esclarecido', permitindo que o material oriundo do tratamento seja utilizado para fins de supervisão, estudo, pesquisas e publicações. Quanto ao modo como ocorrem as triagens, verifica-se que, em algumas clínicas-escola (A, C, D, E, F e G), pacientes devem agendar a entrevista antecipadamente, enquanto em outras ocorre atendimento imediato, conforme esquemas de plantão das equipes ( $\mathrm{B}$ e $\mathrm{H}$ ). Há, de modo geral, uma preocupação com os registros, os quais devem ser realizados pelo triador, e com a supervisão, a partir de relatos dos contatos do triador com o novo paciente. Todavia, mais adiante, veremos que nem sempre tais registros são adequadamente preenchidos pela equipe das clínicas-escola (Tabela 3).

O processo de recepção de um paciente em uma clínica-escola parece ser um dos momentos mais delicados do atendimento e, como tal, vem merecendo atenção por parte de profissionais e pesquisadores que atuam em instituições desse tipo, abrangendo diversas publicações sobre o tema.

Perfeito e Melo (2004) relatam o caso de uma clínica-escola cujos processos de triagem geravam enormes listas de espera por funcionar quase que exclusivamente centrada no ensino. Revisando suas práticas, a clínica-escola voltou suas preocupações às necessidades da comunidade, oferecendo atendimentos em grande quantidade, mas com menos qualidade. Uma nova proposta de triagem, criada para atender ambas as demandas, também não pôde ser efetivada devido às dificuldades de integração e articulação entre os âmbitos acadêmico, técnico e assistencial, gerando a necessidade de repensar e construir uma nova prática.

Salinas e Gorayeb (2002) salientam a necessidade de organizar a clínica-escola para uma melhor recepção dos pacientes, dando respostas precisas quanto à indicação do tratamento, diminuindo o tempo de espera e aumentando a resolução da indicação feita em cada caso. Assim apresentam a 'clínica da recepção', em que psicólogos e residentes intervinham já nos primeiros contatos de triagem, com orientação a pais, familiares ou à equipe médica, também por meio de 'grupos de recepção e acolhimento,' 'grupos de pais' e na própria psicoterapia individual. 
Tabela 3 Distribuição dos pacientes por destino do processo de triagem e por situação final dos atendimentos.

\begin{tabular}{lccccccccc}
\hline Destino do processo de triagem & A & B & C & D & F & G & Total & \% \\
\hline Buscaram atendimento & 541 & 1438 & 200 & 45 & 547 & 299 & 125 & 3372 & 100,00 \\
Foram reencaminhados & 296 & 19 & 10 & 11 & 19 & 7 & 26 & 402 & 11,92 \\
Receberam atendimento ou aguardam em lista de espera & 193 & 470 & 190 & 15 & 424 & 292 & 99 & 1819 & 53,94 \\
Não consta & 52 & 949 & 0 & 19 & 104 & 0 & 6 & 1157 & 34,31 \\
Situação final dos atendimentos & & & & & & \\
Receberam atendimento & 193 & 470 & 190 & 15 & 424 & 284 & 99 & 1811 \\
Abandonaram os atendimentos & 23 & 322 & 39 & 1 & 185 & 74 & 21 & 692 & 38,21 \\
Alta & 6 & 21 & 23 & 14 & 60 & 29 & 24 & 286 & 15,79 \\
Em atendimento ou em lista de espera & 164 & 146 & 128 & 0 & 179 & 181 & 44 & 842 & 46,49 \\
\hline
\end{tabular}

Tabela 4. Critérios que determinam a permanência de pacientes em atendimento nas clínicas-escola.

\begin{tabular}{|c|c|}
\hline Clínicas & Critérios \\
\hline A & $\begin{array}{l}\text { Tipo de doença apresentada } \\
\text { História do desenvolvimento do indivíduo- Aspectos } \\
\text { socioeconômicos } \\
\text { Aspectos psicológicos da família e suas expectativas com } \\
\text { relação ao tratamento } \\
\text { Relação do indivíduo com seu grupo de apoio primário } \\
\text { Observação de aspectos psicomotores, cognitivos e afetivos }\end{array}$ \\
\hline B & $\begin{array}{l}\text { Residir em Porto Alegre } \\
\text { Não pode envolver questões judiciais }\end{array}$ \\
\hline$C$ & $\begin{array}{l}\text { Tipo de doença apresentada } \\
\text { Aspectos socioeconômicos } \\
\text { Ocupação/escolaridade }\end{array}$ \\
\hline D & $\begin{array}{l}\text { Tipo de doença apresentada } \\
\text { História do desenvolvimento do indivíduo } \\
\text { Aspectos socioeconômicos } \\
\text { Relação do indivíduo com seu grupo de apoio primário } \\
\text { Observação de aspectos psicomotores, cognitivos e afetivos }\end{array}$ \\
\hline E & $\begin{array}{l}\text { Tipo de doença apresentada } \\
\text { História do desenvolvimento do indivíduo } \\
\text { Aspectos socioeconômicos } \\
\text { Observação de aspectos psicomotores, cognitivos e afetivos }\end{array}$ \\
\hline $\mathrm{F}$ & $\begin{array}{l}\text { Tipo de doença apresentada } \\
\text { História do desenvolvimento do indivíduo } \\
\text { Aspectos socioeconômicos } \\
\text { Aspectos psicológicos da família e suas expectativas com } \\
\text { relação ao tratamento } \\
\text { Relação do indivíduo com seu grupo de apoio primário }\end{array}$ \\
\hline G & $\begin{array}{l}\text { Tipo de doença apresentada } \\
\text { Aspectos socioeconômicos }\end{array}$ \\
\hline $\mathrm{H}$ & $\begin{array}{l}\text { Tipo de doença apresentada } \\
\text { Aspectos socioeconômicos } \\
\text { Indicação ou não para psicoterapia breve }\end{array}$ \\
\hline
\end{tabular}

O'atendimento imediato de triagem'é proposto por Salinas e Santos (2002) com o intuito de acolher o paciente e responsabilizá-lo por sua própria demanda, e não a corresponder imediatamente. Todavia a extensão do tempo dispendido em cada triagem, associada à dificuldade de recursos humanos para dar conta disso, sugeriu aos autores a idéia de adaptação dessa técnica sob a forma de'grupos de acolhimento', acompanhada de contatos individuais.

Para dar conta da demanda originada em uma lista de espera de cinco anos e meio e dinamizar seu atendimento, Peres (1997) apresenta a modalidade de 'Triagem psicológica grupal'. Essa experiência se mostrou viável e efetiva, agilizando os atendimentos por responder a um grande número de pessoas e por possibilitar um conhecimento diferenciado da demanda.

Ancona-Lopez (1983) descreve que é comum que o paciente conclua a triagem, mas não compareça aos atendimentos, o que ocorreu com 31,1\% da sua amostra. Yehia (1994), ao descrever a população que busca o serviço de atendimento de superdotados em uma clínica psicológica, aponta que $34,0 \%$ desistem dos atendimentos na triagem. Para a autora, isso ocorre porque o triador já esclarece dúvidas dos pais e oferece indicações a respeito das possibilidades de estimulação e dos recursos oferecidos pela comunidade, o que os satisfaz. Os pais, portanto, prescindem do psicodiagnóstico de seus filhos.

Verifica-se (Tabela 4) que são diversos os fatores que determinam se um paciente deve ou não receber atendimento em cada clínica-escola, pois caso não haja o preenchimento dos critérios determinados, deverá ser feito encaminhamento para outra instituição. Os 
critérios estão relacionados às peculiaridades de cada curso de Psicologia, possibilidades dos encarregados da supervisão dos estagiários e peculiaridades de cada comunidade a que atendem. Graminha \& Martins (1994) alertam, também, para a necessidade de que a formação do aluno não seja direcionada a problemas específicos da clientela, mas seja ampla a fim de preparar o estagiário para lidar com problemas diversificados e expandir as possibilidades de sua atuação profissional futura.

Apesar de as clínicas-escola não deverem aceitar indiscriminadamente a clientela que as procura, discernindo motivos de busca de atendimento que são ou não de ordem psicológica, a importância social dessas instituições reside no fato de boa parte das pessoas que buscam auxílio não terem acesso a outros serviços de Psicologia por condições econômicas (a observância de aspectos socioeconômicos está presente em todas as clínicas-escola). Porém quando o critério para permanecer em atendimento nessas instituições não é atendido, não é possível oferecer o serviço ao cliente. Devido ao número restrito de vagas e à impossibilidade de oferecer atendimentos de urgência, ocorrem reencaminhamentos sucessivos para serviços de saúde e de Psicologia (Ancona-Lopez, 1983; Enéas et al., 2000).

A Tabela 4 distribui os pacientes pela situação definida na triagem e pela situação final dos atendimentos ocorridos nas clínicas-escola. Sua análise mostra que a maior parte dos pacientes (53,94\%, relativos a 1.819 sujeitos) recebeu atendimento na própria clínicaescola ou o aguarda em lista de espera. Um número muito elevado de informações faltantes (34,31\% relativos a 1.157 sujeitos) pode comprometer os resultados desta tabela, dado que se torna preocupante, principalmente quanto à ética profissional. É necessária a reformulação do modo como se fazem esses registros, principalmente na clínica-escola B, cujo índice de protocolos em branco é excessivamente grande.

A Tabela 4 também descreve a situação final dos atendimentos realizados no ano de 2004 pelas clínicasescola participantes desta pesquisa. Segundo os dados obtidos, 1.819 pacientes receberam algum tipo de atendimento psicológico nas clínicas-escola, mas esse dado, possivelmente, está comprometido devido às informações faltantes quanto ao destino dos pacientes

370 a partir do processo de triagem, pois não foi possível informar se 34,31\% (1.157 sujeitos) permaneceram em atendimento nas clínicas-escola ou foram encaminhados para outras instituições de saúde ou de atendimento psicológico. Dos pacientes que receberam atendimento nessas clínicas-escola, 38,21\% (692 sujeitos) abandonaram o tratamento, dado esperado com relação à literatura.

Índices de pacientes abandonantes em clínicasescola situam-se entre 30\% a 60\% e o período crucial para os abandonos se dá em torno da sexta sessão. Desse modo, observa-se que a fase inicial da Psicoterapia é a mais delicada para a continuação do tratamento, e os níveis de abandono não se elevam muito depois dessa etapa (Lhullier, 2002). Mesmo assim, muitas vezes, a desistência do paciente pode ser vivida como um fracasso pessoal pelo psicoterapeuta (Figueiredo \& Schvinger, 1981), ainda que o trabalho desenvolvido em um estágio seja sempre o produto da relação entre paciente, estagiário, supervisor e instituição (Peres, 1998).

Os 15,79\% (286 sujeitos) dos pacientes que concluíram os atendimentos com alta representam um percentual elevado, comparando-se aos 4,6\% descritos por Ancona-Lopez (1983). No momento da aplicação do instrumento desta pesquisa, ainda havia pacientes em atendimento ou aguardando em lista de espera, não sendo possível afirmar se o desfecho desses atendimentos será ou não favorável. Mesmo assim, o índice de conclusão dos atendimentos com concordância entre as partes (paciente, terapeuta e supervisor) pode ser considerado elevado.

Também é necessário ressaltar que, nas clínicasescola participantes deste estudo, a equipe é composta por alunos de graduação em Psicologia e por profissionais já formados contratados ou exercendo práticas de pós-graduação. Todavia os índices de atendimentos concluídos por alta podem distinguir-se entre as clínicas-escola por estarem relacionados com os critérios atribuídos para alta por cada uma delas.

É possível perceber as diferenças entre os atributos considerados para a alta entre as clínicasescola participantes deste estudo, como, por exemplo, a conclusão do tratamento no período de um ano, a redução da demanda, a melhoria na auto-estima, a sensação subjetiva de melhora e a concordância entre paciente, terapeuta e supervisor (Tabela 5). Porém destacam-se como fatores comuns a redução dos 
sintomas apresentados no início do tratamento e o fato de serem atingidos os objetivos determinados previamente.

Porém quando o paciente não atinge essa melhora e não é possível concluir o atendimento com alta no momento em que o terapeuta conclui o estágio (por ter período pré-determinado), pode ser necessária a troca de terapeuta, pois o tempo usual para completar um atendimento psicológico é longo, considerando-se poucos os tratamentos concluídos no tempo de estágio do psicoterapeuta em formação (Ancona-Lopez, 1983). Em pesquisa realizada na UCPel, constatou-se que quando é necessário realizar uma mudança de terapeuta, é freqüente que os pacientes abandonem o tratamento. Com o objetivo de reduzir o índice de abandono, foi proposto, com sucesso, um período de co-terapia como adaptação à mudança, no qual são realizadas sessões do paciente com os dois terapeutas (Lhullier, Nunes, Antochevis, Porto \& Figueiredo, 2000). A Tabela 6 descreve como as clínicas-escola realizam esse procedimento.

É possível perceber que a alternativa encontrada por Lhullier et al. (2000) para reduzir os índices de evasão dos atendimentos, quando da necessária troca de terapeuta, também é realizada nas clínicas-escola B, C, E, Fe H. Existem situações em que, para a equipe, é mais indicado o encaminhamento do paciente a outro local de atendimento psicológico ou a outro membro da equipe (quando falamos de clínicas-escola que possuem entre sua equipe profissionais já formados).

Tabela 5. Critérios atribuídos para alta nas clínicas-escola.

\begin{tabular}{|c|c|}
\hline Clínicas & Critérios \\
\hline \multirow[t]{6}{*}{ A } & Atingir de forma satisfatória os objetivos delineados a partir do foco de atendimento \\
\hline & Possibilidade de a pessoa mobilizar novos recursos para lidar de maneira adaptativa com seu momento atual \\
\hline & Maior grau de flexibilidade e criatividade \\
\hline & Esbatimento ou diminuição dos sintomas \\
\hline & Incremento da auto-estima \\
\hline & Possibilidade de retomar um projeto de vida \\
\hline \multirow[t]{2}{*}{ B } & Na ênfase de Psicanálise, a alta está relacionada ao esbatimento da demanda \\
\hline & Na sistêmica, relacionada ao alcance dos objetivos iniciais \\
\hline C & $\begin{array}{l}\text { A clínica-escola oferece tratamento pelo período de até um ano; depois disso o paciente terá alta ou será encaminhado para outro local. Na } \\
\text { psicoterapia cognitivo-comportamental, muitas vezes, a alta se dá em torno de } 12 \text { sessões, dependendo da queixa. }\end{array}$ \\
\hline \multirow[t]{3}{*}{ D } & Evolução satisfatória \\
\hline & Fortalecimento do ego, com a melhora do padrão adaptativo \\
\hline & Resolução do foco trabalhado \\
\hline \multirow[t]{3}{*}{$\mathrm{E}$} & Alívio ou remoção dos sintomas \\
\hline & Resolução parcial ou total do conflito que motivou o tratamento \\
\hline & Alcance da meta estabelecida para o tratamento \\
\hline \multirow[t]{3}{*}{$\mathrm{F}$} & Superação das dificuldades que motivaram a indicação de psicoterapia \\
\hline & Atingir os objetivos contratados no início do processo \\
\hline & Percepção do paciente, do terapeuta e do supervisor sobre o momento \\
\hline G & (não consta a informação) \\
\hline \multirow[t]{3}{*}{$\mathrm{H}$} & Observação da melhora dos sintomas que se apresentavam quando da procura por atendimento \\
\hline & Sensação subjetiva de melhora \\
\hline & Melhor qualidade de vida relatada pelo paciente e/ou seus familiares \\
\hline
\end{tabular}


Tabela 6. Procedimentos realizados pelas clínicas-escola quando o paciente ainda necessita de atendimento psicológico e o período de estágio de seu terapeuta se encerrou.

\begin{tabular}{|c|c|}
\hline Clínicas & Procedimentos \\
\hline \multirow[t]{2}{*}{ A } & O paciente passa a ser atendido por outro estagiário \\
\hline & O paciente é encaminhado para outro local de atendimento \\
\hline \multirow[t]{2}{*}{ B } & O paciente passa a ser atendido por outro estagiário ou outro membro da equipe \\
\hline & É realizado um período de adaptação, em que os dois terapeutas atendem simultaneamente \\
\hline \multirow[t]{3}{*}{ C } & O paciente passa a ser atendido por outro estagiário \\
\hline & O paciente é encaminhado para outro local de atendimento \\
\hline & É realizado um período de adaptação, em que os dois terapeutas atendem simultaneamente \\
\hline \multirow[t]{2}{*}{ D } & O paciente passa a ser atendido por outro estagiário \\
\hline & O paciente é encaminhado para outro local de atendimento \\
\hline \multirow[t]{3}{*}{$E$} & O paciente é encaminhado para outro local de atendimento \\
\hline & O paciente passa a ser atendido por outro estagiário \\
\hline & É realizado um período de adaptação, em que os dois terapeutas atendem simultaneamente \\
\hline \multirow[t]{3}{*}{$\mathrm{F}$} & O paciente é encaminhado para outro local de atendimento \\
\hline & O paciente passa a ser atendido por outro estagiário \\
\hline & É realizado um período de adaptação, em que os dois terapeutas atendem simultaneamente \\
\hline G & Ainda não ocorreu \\
\hline \multirow[t]{2}{*}{$\mathrm{H}$} & O paciente é encaminhado para outro local de atendimento \\
\hline & É realizado um período de adaptação, em que os dois terapeutas atendem simultaneamente \\
\hline
\end{tabular}

\section{Considerações Finais}

Esta pesquisa - que teve como objetivo fazer um levantamento de como são realizados os atendimentos nas clínicas-escola de cursos de Psicologia da região metropolitana de Porto Alegre - trouxe resultados relevantes, mas não conclusivos. Porém constituem o ponto de partida para novas investigações e questionamentos.

A idéia de que nos cursos de graduação em Psicologia no Rio Grande do Sul - por proximidade geográfica com a Argentina e por uma possível conseqüente influência teórica da Psicanálise - a Psicologia Clínica vinha sendo entendida como práticas de orientação psicanalítica mais tradicionais já não pode ser mais afirmada. Nos cursos de graduação em Psicologia, como demonstrado nesta pesquisa, o ensino da Psicologia Clínica, expresso pelas práticas curriculares em estágio, tem-se mostrado ampliado. Não parece haver mais a ênfase nos modelos mais usuais e tradicionais de Psicoterapia, praticados em consultórios particulares e com técnicas voltadas especialmente ao funcionamento e entendimento de uma clientela específica, diferente da clientela característica das clínicas-escola de Psicologia.

A variedade de propostas de intervenção e as abordagens teóricas possibilitam uma gama maior de alternativas para os estagiários vivenciarem o aprendido nas disciplinas, favorecendo a integração teórico-prática.

O deslocamento do psicólogo e a oferta de atendimento para uma parcela maior da população contemplam uma visão integrada do psicólogo como clínico e como profissional da saúde, possibilitando uma interface entre essas áreas na vivência do estagiário: uma experiência prática coerente com as necessidades da população, contemplando as possibilidades atuais de atuação do psicólogo. Essa vivência capacita o aluno pessoal e profissionalmente, considerando o apoio necessário para expressar e supervisionar uma realidade, muitas vezes precária e de muito sofrimento.

Os procedimentos de recepção do paciente na clínica-escola (triagens, acolhimentos) e o uso do termo de consentimento livre e esclarecido expressam 
cuidados éticos relativos à dupla função da clínicaescola, que deve atender com qualidade e respeito o paciente e propiciar reflexões acerca da profissão por parte dos alunos.

Todavia quando analisamos a situação final dos atendimentos nas clínicas-escola participantes deste estudo, percebemos que essas instituições não possuem os registros adequados de seus atendimentos. Isso demonstra uma atitude ambivalente quanto à ética e quanto à preocupação com os atendimentos propriamente ditos na medida em que se mostra importante receber adequadamente o paciente, mas não igualmente importante registrar o destino desse atendimento.

Assim, como considerações finais a este estudo, permanecem mais questionamentos do que respostas. É esperado que, tomando como partida esses resultados, originem-se outras pesquisas uma vez que o retorno dos questionários foi acompanhado de relatos favoráveis dos próprios profissionais responsáveis por algumas clínicas-escola, pois a iniciativa da pesquisa trouxe benefícios para as clínicas-escola, que passaram a questionar o modo como realizam seus registros e a se organizar de forma a facilitar pesquisas futuras, reconhecendo a sua importância.

\section{Referências}

Ancona-Lopez, M. A. (1983). Considerações sobre o atendimento oferecido por clínicas-escola de psicologia. Arquivos Brasileiros de Psicologia, 39 (2), 123-135.

Barbosa, J. I. C., \& Silvares, E. F. M. (1994). Uma caracterização preliminar das clínicas-escola de Fortaleza. Estudos de Psicologia (Campinas), 11 (3), 50-56.

Bardin, L. (1988). Análise de conteúdo. Lisboa: Edições 70.

Brasil (27 de agosto de 1962). Lei no 4.119, que dispõe sobre a formação em Psicologia e regulamenta a profissão de Psicólogo. Capítulo IV (Artigo 16, p.3). Acessado em abril 12, 2004, disponível em: http://www.pol.org.br/ legislacao/pdf/lei_n_4.119.pdf

Campezatto, P. von. M., Menegat, C. B., Nunes, M. L. T., \&Vitola, J. C. O. (2005). Interface entre a Psicologia Clínica e a Psicologia da Saúde no Serviço de Atendimento Psicológico da PUCRS. In L. L. Melo-Silva, M. A. Santos \& C. P. Simon. Formação em psicologia: serviços-escola em debate (pp.103-122). São Paulo: Vetor Editora.
Carvalho, M. J. C., \& Telles, S. R. A. (2001). Considerações sobre queixas de pacientes em triagens de clínica-escola. Psikhê, $6(1), 7-14$

Dirani, C. C. (2000). Intervenções breves: uma proposta de atendimento psicológico no PIPAS. In V. L. Bemvenuti (Org.), Cadernos de Extensão II. Universidade do Vale do Rio dos Sinos. Pró-Reitoria Comunitária e de Extensão. Diretoria de Extensão (pp.53-64). São Leopoldo: Unisinos.

Enéas, M. L. E., Faleiros, J. C., \& Sá, A. C. A. (2000). Uso de psicoterapias breves em clínica-escola: caracterização dos processos com adultos. Psicologia: Teoria e Prática, 2 (2), 9-30.

Figueiredo, M. C., \& Schvinger, A. A. (1981). Estratégias de atendimento psicológico-institucional a uma população carente. Arquivos Brasileiros de Psicologia, 33 (3), 46-57.

Furtado, H. M. R. (1997). Disciplina de psicologia clínica: estudo de planos de ensino em universidades do Rio Grande do Sul. Dissertação de mestrado não-publicada, Pontifícia Universidade Católica do Rio Grande do Sul, Porto Alegre.

Ghazzi, M. S. (2000). Estimulação precoce: características do trabalho nas APAEs do Rio Grande do Sul. Dissertação de mestrado não-publicada, Pontifícia Universidade Católica do Rio Grande do Sul, Porto Alegre.

Gil, A. C. (1999). Métodos e técnicas de pesquisa social. São Paulo: Atlas.

Goodwin, J. C. (1995). Research in psychology: methods and design. New York: John Wiley.

Graminha, S. S. V., \& Martins, M. A. O. (1991). Um serviço de inscrição para atendimento psicológico infantil estruturado com vistas à formação do aluno do curso de psicologia. Estudos de Psicologia (Campinas), 2 (8), 189-201.

Graminha, S. S, V., \& Martins, M. A. O. (1994). Procura de atendimento psicológico para crianças: características da problemática relatada pelos pais. Psico (Porto Alegre), 25 (2), 53-79.

Guerrelhas, F. F., \& Silvares, E. F. M. (2000). Grupos de espera recreativos: proposta para diminuir o índice de evasão em clínica-escola de psicologia. Temas em Psicologia da SBP, 8 (3), 313-321.

Güntert, A. E. V. A., Camargo, C., Fabriani, C. B., Silva, S. M., Conti, J., Dias, C. C., Zanetti, F., \& Silva, T. C. (2000). As variáveis determinantes na aderência à psicoterapia: uma investigação em clínica-escola. Psico USF, 5 (2),13-23.

Henriques, M. A. L. (1998). Fortalecimento egóico observado em idosos submetidos à psicoterapia grupal em clínica escola. Psicologia Revista (São Paulo), (6), 135-141.

Lhullier, A. C. (2002) . Abandono de tratamento em psicoterapias realizadas numa clínica-escola. Tese de doutorado nãopublicada, Pontifícia Universidade Católica do Rio Grande do Sul, Porto Alegre.

Lhullier, A. C., Nunes, M. L. T., Antochevis, A. F., Porto, A. M., \& Figueiredo, D. (2000). Mudança de terapeuta e abandono de psicoterapia em uma clínica-escola. Aletheia, (11), 7-11. 
Mejias, N. P. (1995). Atuação do psicólogo: da clínica para a comunidade. Cadernos de Psicologia (São Paulo), (1), 32-43.

Peres, V. L. A. (1997). Triagem Psicológica Grupal: procedimento e resultados obtidos com lista de espera de crianças, adolescentes e adultos, em uma clínica-escola de psicologia. Paidéia, (12/13), 63-76.

Peres, W. S. (1998). A instituição do estágio: uma reflexão sobre os analisadores. Psicologia em Estudo, 3 (2) 163-176.

Perfeito, H. C. C. S., \& Melo, S. A. (2004). Evolução dos processos de triagem psicológica em uma clínica-escola. Estudos de Psicologia (Campinas), 21 (1), 33-42.

Ramires, V. R. R. (2000). A psicoterapia psicanalítica no contexto da extensão universitária. In V. L. Bemvenuti (Org.), Cadernos de Extensão /l (pp.19-27). São Leopoldo: Unisinos.

Romaro, R. A., \& Capitão, C. G. (2003). Caracterização da clientela da clínica-escola de Psicologia da Universidade de São Francisco. Psicologia: Teoria e Prática, 5 (1), 111-121.

Salinas, P., \& Gorayeb, R. (2002). Caracterização funcional de uma clínica-escola de psicologia médica. Aletheia, (16), 83-95.

Salinas, P., \& Santos, M. A. (2002). Serviço de triagem em clínica-escola de Psicologia: a escuta analítica em contexto institucional. Psychê, 6 (9), 177-196.

Santos, M. A. (1990). Caracterização da clientela de uma clínica psicológica da prefeitura de São Paulo. Arquivos Brasileiros de Psicologia, 42 (2), 79-94.
Schmidt, M. L. S. (1992). Clínica-escola, escola da clínica? Boletim de Psicologia, 42 (96/97), 99-103.

Seidl, E. M. F., \& Costa Júnior, A. L. (1999). O Psicólogo na Rede Pública de Saúde do Distrito Federal. Psicologia Teoria e Pesquisa (Brasília), 15 (1), 27-35.

Silvares, E. F. M. (1993). O papel preventivo das clínicas-escola de Psicologia em seu atendimento a crianças. Temas em Psicologia, 2, 87-97.

Silvares, E. F. M. (1996). É satisfatório o atendimento psicológico nas clínicas-escolas brasileiras? In R. M. L. L. Carvalho (Org.), Repensando a formação do psicólogo: da informação à descoberta - Coletâneas da ANPEPP (pp.137-145). Campinas: Alínea.

Silvares, E. F. M. (2000). Invertendo o caminho tradicional do atendimento psicológico numa clínica-escola brasileira. Estudos de Psicologia (Natal), 5 (1), 149-180.

Terzis, A., \& Carvalho, R. M. L. L. (1988). Identificação da população atendida na clínica-escola do Instituto de Psicologia da PUCCamp. Arquivos Brasileiros de Psicologia, 40 (4), 87-97.

Yehia, G. Y. (1994). Caracterização da clientela que procura o seriço de identificação de superdotados numa clínica psicológica. Estudos de Psicologia (Campinas), 11 (3), 3-9.

Recebido em: 30/1/2006

Versão final reapresentada em: 13/6/2006

Aprovado em: 21/7/2006 